\title{
POLYHOMOA AZUMA, A SYNONYM OF KYIDRIS BROWN (HYMENOPTERA: FORMICIDAE)
}

\author{
By William S. Creighton
}

Dept. of Biology, College of the City of New York

During April of 1950 the writer received from Professor Masao Azuma of Nishinomiya, Hyogo Prefecture, Japan, a short paper dealing with Japanese ants. The paper is a separate from Volume 1, No. 4 of a publication entitled Hyogo Biology. Its pages are numbered 34-37 and it bears the date 30 Aug. 1949. As I shall subsequently show, this date is the acceptance date of the article, not its date of publication.

As the paper is almost entirely in Japanese I could make little of it other than to note that it carries the original description of a new genus Polyhomoa. Some weeks later Dr. Wm. Brown, who had meanwhile had the paper translated into English, informed me that Polyhomoa is the same as his Kyidris and that, if the date on the reprint represents its time of publication, Azuma's name would take precedence. The original description of Kyidris Brown was published in the Japanese journal Mushi in the issue which appeared on September 20, 1949 (Vol. 20, pars 1, p. 3.) Dr. Brown made various efforts to learn the significance of the date on Azuma's article. The only positive response came from Dr. Yasumatsu, to whom Dr. Brown had applied for information. According to Dr. Yasumatsu the date of publication of Hyogo Biology, Volume 1, No. 4 was January 10, 1950. This strongly suggested that the date carried on Azuma's article was an acceptance date. The verification of this surmise required access to the entire number of Hyogo Biology containing Azuma's article. With the distribution of the journal restricted to Japan, this possibility seemed remote. However Miss Hazel Gay, the Librarian of the American Museum of Natural History became interested in the problem and was able to secure a full file of Hyogo Biology (Volume 1, Nos. 1-4) for the Museum library. As nearly as can be ascertained, this is the only set of this journal in the United States and Miss Gay is to be congratulated on the success of her efforts.

The articles which compose the Number 4 issue of Hyogo Biology are separately dated during the year 1949. The dates run from 
March to September, at which time the number was apparently closed and sent to the printer. The printing of the issue consumed three months. In consequence, the cover bears the date of publication, January 10, 1950.

This being the case, the genus Kyidris Brown takes precedence over the synonymic genus Polyhomoa Azuma. As to whether Azuma's species itoi is a synonym of Brown's mutica is not certain but it seems probable that this is the case.

Massachusetts Records of Cyphoderus assimilis Borner (ColLEMBоLA).-During the last three years, specimens of this species have been recovered in the field from ant nests in four localities in Massachusetts. The species has been taken from Annisquam in May, June, and July, from Boston in September, from Swampscott in September, and from Cambridge in October. In the New World this species is ordinarily found in tropical and subtropical areas, and when taken in more northerly regions it is usually in such artificially sheltered areas as greenhouses. Its occurrence in Massachusetts may be only a local invasion, but that this has been successful to some extent is shown by the recovery of specimens in one area (Annisquam) in three successive years. Although the species has not been found outside of ant nests, it shows little selectivity as to the ant, having been found in nests of Aphaenogaster, Acanthomyops, Chthonolasius, Lasius, and Tetramorium.-K. A. Christiansen, Biological Laboratories, Harvard University. 

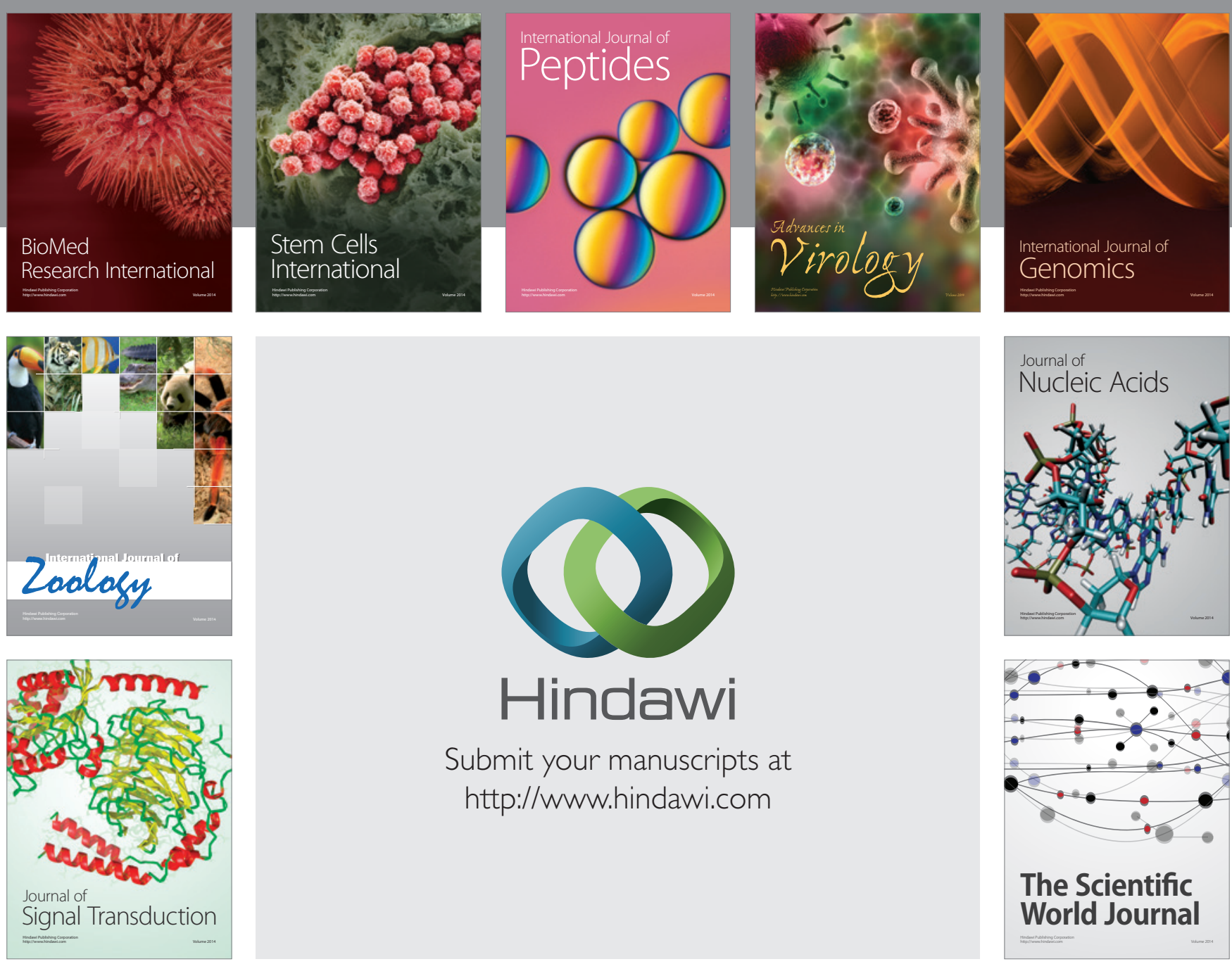

Submit your manuscripts at

http://www.hindawi.com
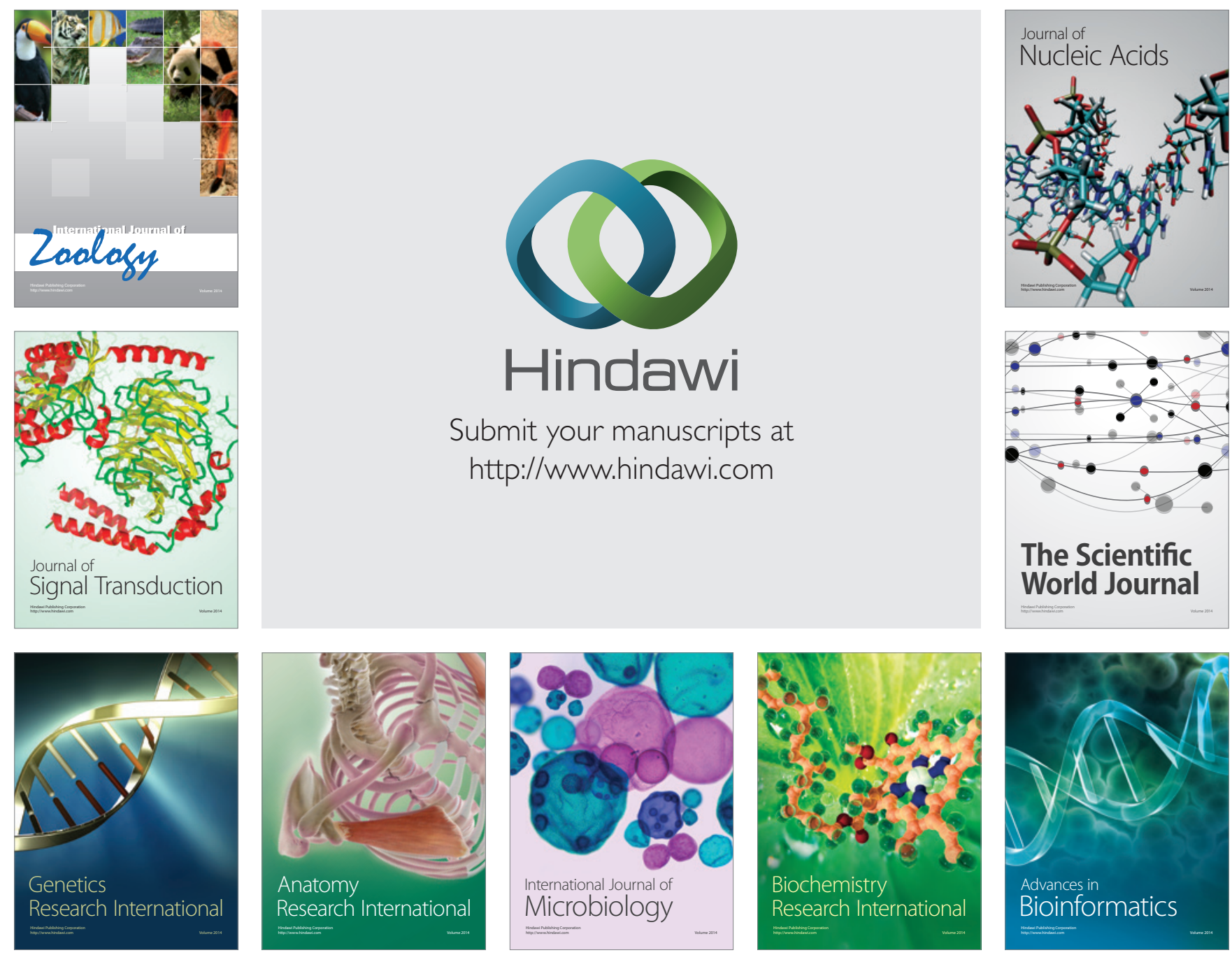

The Scientific World Journal
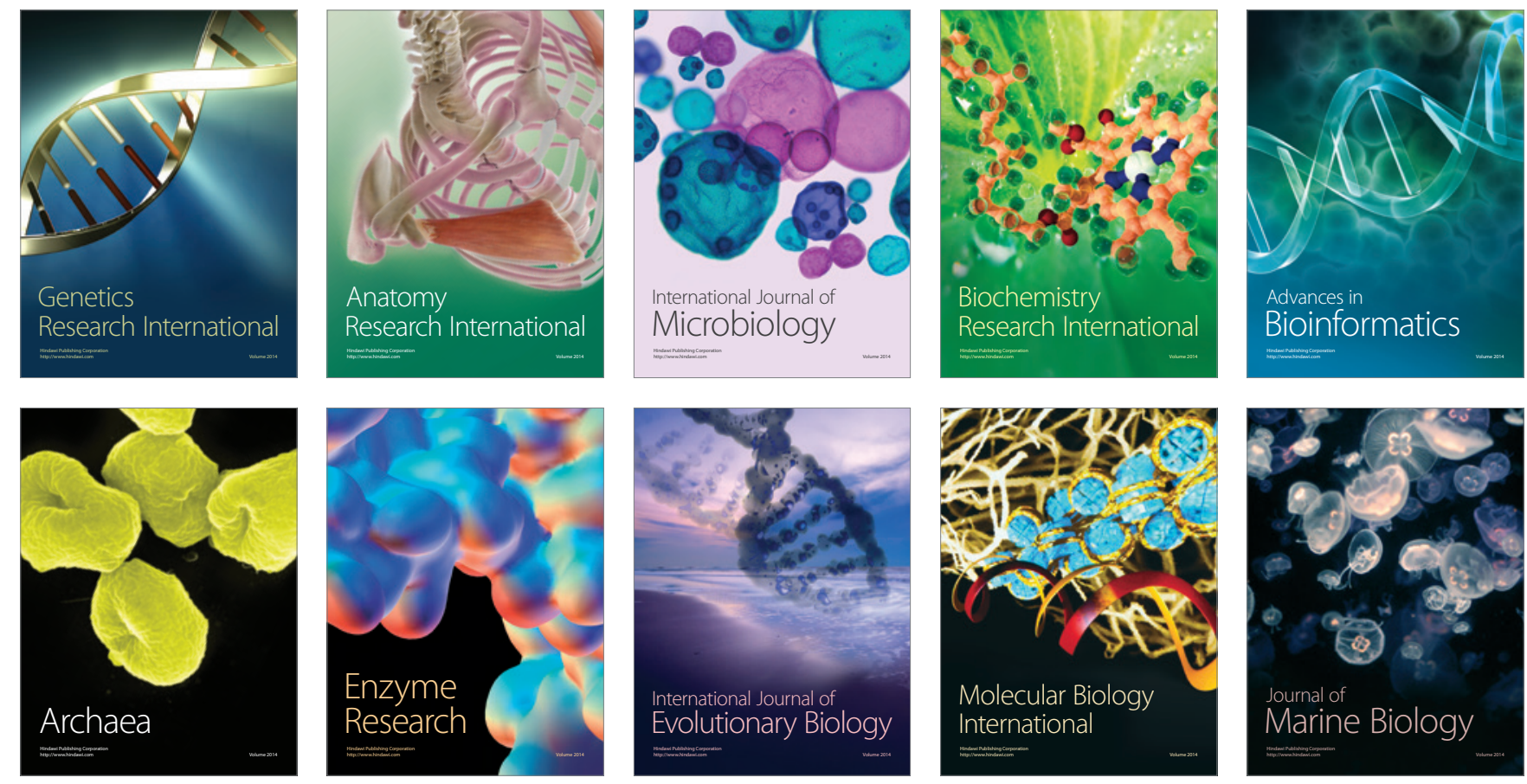